\title{
Questes
}

\section{Les manifestations divines : avant-propos}

\section{Élisabeth Gaucher-Rémond}

\section{(2) OpenEdition}

\section{Journals}

Édition électronique

URL : http://journals.openedition.org/questes/977

DOI : 10.4000/questes.977

ISSN : 2109-9472

\section{Éditeur}

Les Amis de Questes

\section{Édition imprimée}

Date de publication : 15 septembre 2010

Pagination : 1-4

ISSN : 2102-7188

\section{Référence électronique}

Élisabeth Gaucher-Rémond, « Les manifestations divines : avant-propos », Questes [En ligne], 19 |

2010, mis en ligne le 01 janvier 2014, consulté le 25 septembre 2020. URL : http://

journals.openedition.org/questes/977 ; DOI : https://doi.org/10.4000/questes.977 


\section{Avant-propos}

\section{Élisabeth GAUCHER-REMOND \\ (Professeur à l'Université de Nantes)}

Si la société de l'Occident médiéval semble «imprégnée de Dieu », elle n'en éprouve pas moins une «frustration » dans son désir d'entrer en relation directe avec Lui. Cette aspiration aurait même conduit à une quête plus personnelle du divin, en dehors du culte et des sacrements administrés par l'Église: l'institution ecclésiale, toujours ressentie comme indispensable à la quête du salut et à la vénération collective, ne satisfait plus les besoins d'une dévotion individuelle, où chacun espère le bénéfice d'une révélation privée ${ }^{1}$.

Pourtant, depuis l'Ancien Testament, on sait que l'homme ne peut contempler Dieu dans le monde des vivants. «Tu ne peux pas voir ma face, car l'homme ne peut me voir et vivre» : ainsi parle Yahvé à Moïse ${ }^{2}$. C'est une faveur exceptionnelle, accordée tout particulièrement à $\mathrm{Moïs}^{3}$ et à Élie $^{4}$, que de s'entretenir avec Dieu et d'assister à la Transfiguration du Christ $^{5}$, du Fils par qui se manifeste, dans le Nouveau Testament, la gloire du Père. Pour les hommes, le face à face avec Dieu ne peut avoir lieu ici bas : il est réservé à l'au-delà de la mort, promesse sur laquelle repose toute l'eschatologie chrétienne. À ce principe de l'invisibilité de Dieu, voire de son incognoscibilité, la pensée philosophique de la contemplation associe une cause tout humaine: les ténèbres du corps et de l'intelligence, qui

\footnotetext{
${ }^{1}$ Jacques Le Goff, Le Dieu du Moyen Âge, Paris, Bayard, 2003, p. 72, 74, 84.

${ }^{2}$ Ex 33, 20.

${ }^{3}$ Ex 33, 11: «Yahvé parlait à Moïse face à face, comme un homme parle à son ami... ». Mais devant le buisson ardent, « Moïse se voila la face, car il craignait de fixer son regard sur Dieu » $(E x 3,6)$.

${ }^{4} 1 R 19,13$ : ayant entendu les signes de la présence de Yahvé, Élie « se voila le visage avec son manteau, il sortit et se tint à l'entrée de la grotte. Alors une voix lui parvint....».

${ }^{5} M t, 17,3$ : «Et voici que leur apparurent Moïse et Élie, qui s’entretenaient avec lui ».
} 
entravent la perception immédiate du divin. Aussi Dieu, par l'exercice de sa « condescendance », adapte-t-il ses manifestations à la perception qu'en peuvent avoir ses destinataires, tandis que s'élabore, aux $\mathrm{XIII}^{\mathrm{e}}$ et $\mathrm{XIV}^{\mathrm{e}}$ siècles, une hiérarchie des différents modes d'accès au divin : si la « vision immédiate » n'est accessible qu'aux bienheureux, la « vision abstractive », intellectuelle, et la «mystique affective» s'offrent comme des voies d'approche ${ }^{6}$. La plus grande disponibilité est requise, pour qui veut lire, dans le monde sensible, les signes de la présence divine. Dans son traité sur les invisibles de Dieu (la puissance du Père, la sagesse du Fils, la bonté de l'Esprit-Saint), Hugues de Saint-Victor invite à dépasser le monde des apparences extérieures pour en comprendre la raison : « la puissance est manifestée par l'immensité de la création, la sagesse par sa beauté [decor], la bonté par son utilité $»^{7}$.

Mais la question des manifestations divines pour l'homme du Moyen Âge ne se pose pas seulement en termes bibliques ou théologiques; elle revêt aussi, dans les contextes politiques et militaires, une dimension probatoire et peut aboutir à des choix pragmatiques, où l'interprétation des interventions du Ciel dans les affaires humaines motive la quête d'un soutien infaillible. On a pu y voir un argument dans l'évangélisation des païens et la conversion de la Gaule : «pour eux (...), le problème se posait en termes d'efficacité : si le Dieu des Chrétiens leur procurait la victoire sur leurs adversaires, pourquoi ne pas reconnaître sa supériorité et adhérer à son culte ? $»^{8}$. De même, le rayonnement des saints thaumaturges et

\footnotetext{
${ }^{6}$ Christian Trottmann, «Vision de Dieu », dans Dictionnaire du Moyen Âge, Claude GAUVARD, Alain DE LiBerA et Michel ZINK (dir.), Paris, PUF, «Quadrige », 2002, p. 1460-62.

${ }^{7}$ Hugues de Saint-Victor, Des trois invisibles, I, P.L., t.176, 811-B-813A : traduction par Alain Michel dans Théologiens et mystiques au Moyen Âge. La Poétique de Dieu ( $V^{e}-X V^{e}$ siècles), Paris, Gallimard, «Folio », 1997, p. 344.

${ }^{8}$ André VAuchez, «L'idée de Dieu », La France médiévale, Jean FAVIER (dir.), Paris, Fayard, 1983, p. 468.
} 
protecteurs aurait joué un rôle déterminant dans l'essor du christianisme9 .

Dans le champ de la littérature, tous les genres s'essaient à l'expression des manifestations divines: non seulement l'hagiographie mais aussi les œuvres profanes et fictionnelles, au point qu'il nous semble permis d'élargir à tous ces registres la question qui fut posée aux romans du Graal : « la fiction (...) peut-elle investir le domaine réservé de l'exégèse et de la représentation sacrées ? Peut-elle à son tour prétendre dire l'indicible, figurer l'infigurable? $»^{10}$. Quant aux modes d'intervention attribués à Dieu, force est de constater leur diversité littéraire : apparitions d'anges ou de songes prémonitoires dans les chansons de geste ${ }^{11}$, prédictions, miracles ou phénomènes météorologiques dans l'historiographie ${ }^{12}$, décors et trucages de théâtre ${ }^{13}$, lettre tendue du Ciel dans les récits de conversion ${ }^{14} \ldots$ autant de manifestations qui sollicitent aussi bien la vue que l'ouïe. Mais toute « semblance » appelle à une quête de la « senefiance ». Ce rapport entre le signifiant et le signifié, qui conditionne la vision et l'intelligence de la révélation, est au cœur de la fiction graalienne, où dialoguent la voix des

\footnotetext{
${ }^{9}$ Ibid., p. 468-470.

10 Mireille Seguy, Les Romans du Graal ou le Signe imaginé, Paris, Champion, « NBMA », 58, 2001 p. 12.

${ }^{11}$ Voir Sommeil, songes et insomnies, Actes du colloque des Universités de Rennes 2 et Brest-Bretagne Occidentale (Rennes, 28-29 septembre 2006) publiés par Christine FERlAMPIN-ACHER, Élisabeth GAUCHER et Denis Hüe, Perspectives médiévales (Société de langues et de littératures médiévales d'oc et d'oïl), 2008.

${ }^{12}$ Pour ne citer qu'un exemple, on mentionnera les présages, heureux ou inquiétants, que mentionne le Bourgeois de Paris, spectateur d'un «monde plein de signes que l'homme ne sait pas déchiffrer» (Colette BEAune, Journal d'un Bourgeois de Paris, introduction, Paris, Le Livre de Poche, «Lettres gothiques », 1990, p. 24).

${ }^{13}$ Certains d'ailleurs ne fonctionnent pas : ainsi l'envol de pigeons pour manifester la descente du Saint Esprit dans le Mystère du Vieil Testament (1541), analysé par Véronique Dominguez ( «Entre la feinte et le rire: les supplices sur la scène des mystères $\left(\mathrm{XV}^{\mathrm{e}}-\mathrm{XVI}^{\mathrm{e}}\right.$ siècles) », CAMAREN (Cahiers Moyen Âge - Renaissance), 3, 2010, p. 122).

${ }^{14}$ Voir l'analyse du motif par Fanny Oudin, dans le présent volume. On peut y rattacher l'exemple de Robert le Diable, où les clauses de la pénitence du héros sont transmises par un « brief » qu'une main céleste tend à l'ermite ayant écouté la confession de Robert (éd.-trad. Élisabeth GAUCHER, Paris, Champion Classiques, "CCMA », 17, 2006, v.1081).
} 
théologiens et celle des romanciers ${ }^{15}$ : le Graal se substitue à la montagne biblique, lieu de la rencontre entre Dieu et Moïse, pour devenir « le point de contact » entre Dieu et le chevalier élu ${ }^{16}$.

Sanctuaires, récits apocryphes, spéculations philosophiques, histoire dynastique, légendes, miracles et romans sont autant de champs d'observation d'où procèdent les analyses du présent volume, qui nous donnent à voir la représentation et la perception des manifestations divines, du haut Moyen Âge aux Temps modernes.

${ }^{15}$ Voir Jean-René VAlette, La Pensée du Graal. Fiction littéraire et théologie (XII XIII siècle), Paris, Champion, " NBMA », 85, 2008.

${ }^{16}$ Ibid., p. 301-302. 